\title{
Renal Arterial Doppler Resistive Index in Differentiating Obstructive and Non-Obstructive Hydronephrosis in Children at Tikur Anbessa Specialized Hospital, Ethiopia, October, 2018
}

\author{
Daniel Zewdneh Solomon ${ }^{1 *}$, Ayana Wasse ${ }^{1}$ Yocabel Gorfu $^{1}$
}

\author{
OPEN ACCESS
}

Citation: Daniel Zewdneh Solomon, Ayana Wasse Yocabel Gorfu. Renal Arterial Doppler Resistive Index in Differentiating Obstructive and NonObstructive Hydronephrosis in Children at Tikur Anbessa Specialized Hospital, Ethiopia, October, 2018. Ethiop J Health Sci.2019;29(5):591.doi:http://dx.doi.org/

10.4314/ejhs.v29i5.9

Received: April 8, 2019

Accepted: June 3, 2019

Published: September 1, 2019

Copyright: (C) 2019 Daniel Zewdneh Solomon, et al. This is an open access article distributed under the terms of the Creative Commons Attribution License, which permits unrestricted use, distribution, and reproduction in any medium, provided the original author and source are credited.

Funding: Nil

Competing Interests: The authors declare that this manuscript was approved by all authors in its form and that no competing interest exists.

Affiliation and Correspondence:

${ }^{1}$ Department of Radiology, School of Medicine, College of Health Sciences, Addis Ababa University, Ethiopia

*Email:dzewdnehsolomon@yahoo. com;danielzewdnehsolomon@gmai 1.com

\section{ABSTRACT}

BACKGROUND: Most congenital anomalies of the urinary tract present with hydronephrosis. Some are physiological while others pathological. Ultrasound, micturating cyst urethrography, dynamic renal scintigraphy, intravenous urography, dynamic and static magnetic resonance urography are used for examination. Currently, renal arterial Doppler resistance index is used as complimentary mechanism. This study assesses our experience in resistive index measurement in differentiating obstructive from non-obstructive hydronephrosis in children. METHODS: A cross-sectional study of forty-two infants and children ( $<14$ years) with hydronephrosis were enrolled using consecutive sampling. Ultrasonography to assess the degree of hydronephrosis and avoiding cystourethrogram were used for the diagnosis of vesicoureteral reflux and posterior urethral valve. Intravenous urogram and surgery were used to confirm causes for obstructive hydronephrosis. Doppler ultrasonography assessed both kidneys to determine mean resistive index for both obstructive and non-obstructive hydronephrosis as well as nonobstructive kidneys. Independent t test was used for analysis at $p<0.005$. RESULTS: The major cause for obstructive hydronephrosis was pelviuretheric junction obstruction (47.6\%) followed by posterior urethral valve (16.7\%). For non-obstructive hydronephrosis, vesicoureteral reflux was the main cause followed by prune belly syndrome. The mean resistive index for non-hydronephrotic kidneys was $0.6654 \pm 0.053$, for nonobstructive hydronephrotic ones was $0.6825 \pm 0.06668$ and obstructive ones was $0.7791 \pm 0.11977$. The mean resistive index difference between the obstructive and non-obstructive hydronephrosis was 0.09661 with standard error of difference 0.02443. The difference was statistically significant $(P-<0.001)$. A mean RI ROC curve showed sensitivity, specificity and accuracy of $71.1 \%, 81.2 \%, 75.4 \%$ respectively $(p=0.003)$. CONCLUSION: This study has shown that the mean renal arterial resistive index was significantly higher in obstructive hydronephrotic kidneys than non-obstructive hydronephrotic kidneys. This can be a valuable tool for diagnosis and follow-up after intervention.

\section{INTRODUCTION}

There is always a dilemma of differentiating a non-obstructed dilated system, where hydronephrosis $(\mathrm{HN})$ will regress spontaneously over time (or remain stable) from a dilated but obstructed system. 
Diagnosis should be intervention done before renal damage occurs. The clinician has to established early and choose

conservative approach and surgical management through appropriate investigations with minimal radiation and invasive techniques to prevent renal damage (1).This study is intended to assess the clinical role of Doppler ultrasound for differentiating obstructive from non-obstructive $\mathrm{HN}$ depending on resistive index difference.

The differentiation between transient $\mathrm{HN}$ versus clinically significant ureteropelvic junction obstruction (UPJ) poses challenges in pediatric urology. The incidence of transient $\mathrm{HN}$ ranges from 41 to $88 \%(2,3)$. The incidence of UPJ obstruction in children with antenatal hydronephrosis (ANH) is approximately $10-30 \%$. A few retrospective studies reported a surgical intervention rate of $38-52 \%$. Other randomized trials suggested that only $19-25 \%$ of the children with prenatally diagnosed UPJ obstruction require surgical intervention, indicating the majority are not obstructive in nature (4-7).

HN may suggest the possibility of vesicoureteric reflux (VUR) occurring in $10-20 \%$ of patients with prenatal HN (8). In one prospective study, $15 \%$ of the children with mild prenatal hydronephrosis had VUR while $43 \%$ of these had a normal postnatal renal US scan. (9)

Uretero-vesicaljunction (UVJ) obstruction (megaureters) can be refluxing, obstructed or nonrefluxing/non-obstructed,

refluxing/obstructed. About $72 \%$ will spontaneously resolve during postnatal follow-up. Posterior urethral valve (PUV) is another important cause of obstruction (10-12). The above clinical conditions are examples where Doppler has a role in the follow-up monitoring of patients to avoid unnecessary surgery. US, IVU, VCUG, nuclear renal scintigraphy and excretory phase $\mathrm{T} 1-$ weighted Magnetic Resonance Urography (MRU) give morphological and functional information $(13,14)$.

Renal Doppler US has been in complimentary diagnostic use in addition to the above-mentioned diagnostic tools. In neonates, probably concurrent with the physiologic low glomerular filtration rate, the resistance of the renal arterial bed is somewhat higher: $\mathrm{RI}=0.7$ to 0.8 (normal adult resistive index RI $0.65 \pm 0.10$ ) because there is a range of normal
RI values, the diagnosis of abnormal intrarenal resistance is much more reliably made by comparing wave forms from the pathologic kidney with those of the normal kidney (15).

Platt et al et al defined a good discriminatory value to differentiate obstructive from nonobstructive dilatation in a large series of patients, including 70 with pyelocaliectasis. In the 38 obstructed kidneys, the mean resistive index $(0.77$ $\pm 0.05)$ was elevated compared to that of 32 with non-obstructive dilatation (mean $0.63 \pm 0.06$ ). They plotted a receiver operating curve that identified 0.70 as an optimal discriminatory resistive index value. This threshold value achieved $92 \%$ sensitivity, $88 \%$ specificity and $90 \%$ overall accuracy in diagnosing the presence or absence of obstruction in the adult population (16).

Misni et al also evaluated 16 children with renal Doppler and found that RI was different between obstructive (mean RI 0.78) and nonobstructive HN (mean RI of 0.70). The difference was statisticaly significant $(\mathrm{p}<0.05)(17)$.

It is now generally accepted that RI is an agedependent parameter. Bude showed that infants younger than 6 months of age had significantly higher mean RI values than adults. In this age group, the probability of an index greater than 0.70 was as high as $57 \%$. Values also tended to decrease with increasing age, approaching adult levels at about year 4, and by age 7, equal those of adults (18) Doppler ultrasound as a follow-up tool can show the relief of obstruction after reconstructive surgery, stone passage, or placement of a stent or nephrostomy tube through normalization of the resistive index (19-24). The purpose of this study is, therefore, to explore this experience in our diagnostic setup.

\section{SUBJECTS AND METHODS}

This cross-sectional descriptive study was conducted at Tikur Anbessa Specialized Hospital (TASH), Department of Radiology, from November, 2017 to July, 2018. The source population was all children referred to our hospital while the study population was all children (newborns to 14 years of age) diagnosed with

DOI: http://dx.doi.org/10.4314/ejhs.v29i5.9 
hydronephrosis and sent for ultrasound. Children who had concurrent medical renal diseases were excluded.

A non-random convenient sampling was used, and for the purpose of determining mean RI difference between obstructive and non-obstructive hydronephrosis. The sample size was calculated using comparison between two groups when endpoint is quantitative data using the formula: $n$ $=\left(\mathrm{s}_{1}{ }^{2}+\mathrm{s}_{2}{ }^{2}\right) \mathrm{f}(\alpha, \beta) /\left(\mathrm{m}_{1}-\mathrm{m}_{2}\right)^{2} ; \quad \alpha=0.05$ (two sided), $Z=1.96$ and power of study is assumed $90 \%$ value of $\beta=1.282$; using an approach as used by a similar Malaysian study(17) The sample size obtained was 42. A Sonoace ultrasound machine with a 3.5-6 MHz frequency sector transducer was used for older and heavy children and linear high frequency $6.9-11 \mathrm{MHz}$ transducer for neonates and small children. Renal arteries at the hilum were approached trans-abdominally anteriorly or translumbar posteriorly. Doppler interrogation was done on both hydronephrotic and nonhydronephrotic kidneys. Data were filled in a structured format. Grading of hydronephrosis was documented according the Society of Infant Ultrasound (SFU) system (19). Patients' medical files were reviewed for demographic and clinical information.

Data were entered in to SPSS version 25.0 software package and appropriate descriptive and analytic statistics were done. Analysis using independent $\mathrm{t}$ test for mean difference of $\mathrm{RI}$ between obstructive and non-obstructive hydronephrosis at $\mathrm{P}$-value of $<0.05$ with $95 \%$ confidence interval (CI) was used. Receiver operative characteristic curves were constructed to demonstrate sensitivity, specificity and diagnostic accuracy of Doppler mean RI in differentiating obstructive HN from non-obstructive HN. Results were displayed in frequency tables, and charts.Written ethical approval and consent were obtained from the Ethical Review Committee, and study subjects and their caretakers, respectively.

\section{RESULTS}

A total of 42 children were scanned for gross grading of hydronephrosis and Doppler assessment of RI. Among them, 31(73.8\%) were males and 11(26.2\%) were females. The age of the participants ranged from 0-14 years with a mean age of $4.43 \pm 4.11$ years, and a median of 4.75 years. Then, 28(62\%) participants had unilateral and $16(38 \%)$ bilateral hydronephrosis. A total of 61 kidneys were hydronephrotic of which obstructive ones accounted for 45(73.8\%).

Obstructive hydronephrosis was detected in $66.7 \%$ postnatally and $33.3 \%$ prenatally. The proportion detected prenatally was caused by PUJ obstruction and PUV comprising $47.6 \%$ and $16.7 \%$, respectively. For non-obstructive hydronephrosis, VUR was the main cause followed by prune belly syndrome and bladder exstrophy. Two patients had masses (one neuroblastoma and the other ovarian tumor), and one patient had retroperitoneal fibrosis (Figure 1).

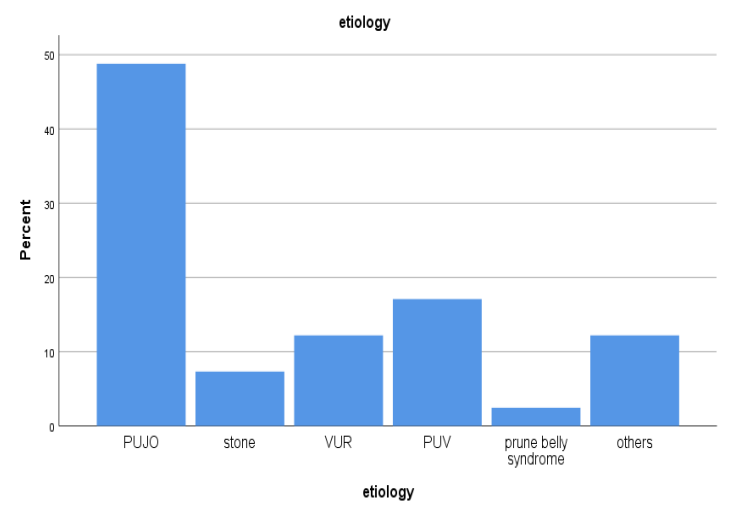

Figure 1: Etiology of hydronephrosis among children in TikurAnbessa specialized hospital $(n=42)$, October, 2018

For the cause of hydronephrosis detected by ultrasound; confirmation was done with IVP for PUJ obstruction in 10(23.8\%). VCUG was performed to confirm posterior urethral valve and VUR in $16(35.7 \%)$. Surgery alone was used to confirm cause in $14.3 \%$ while IVP+surgery were confirmatory in $9.5 \%$. Contrast enhanced CTconfirmed the diagnosis of one neuroblastoma, one ovarian mass and one retroperitoneal fibrosis (Figure 2). Concerning severity of hydronephrosis, moderate hydronephros occurred in $54.8 \%$ while mild and severe ones were seen in $14.3 \%$ and $31 \%$, respectively, in keeping with the SFU grading system. 


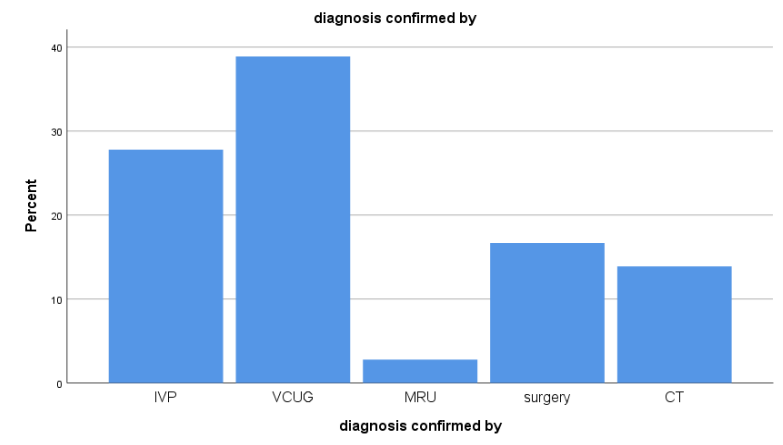

Figure 2: Hydronephrosis confirmation diagnosis among children in TikurAnbessa specialized hospital ( $n=42)$, October, 2018.
The mean resistive index for non-hydronephrotic kidneys was $0.6654 \pm 0.053$, for non-obstructive hydronephrotic kidneys $0.6825, \pm 0.06668$ and for obstructive kidneys of $0.7791 \pm 0.11977$ (Table 1).

The mean RI difference between the obstructive and non-obstructive hydronephrosis was 0.09661 with standard error of difference 0.02443 . Statistical significance was tested with students independent $\mathrm{t}$ test with $\mathrm{p}$-value of $<$ 0.0001 and CI $(0.04749,0.1457)$ where critical tvalue of 2.01 and calculated t-value of 3.955 .

Table 1: Mean RI of hydronephrotic kidneys among children in TikurAnbessa Specialized Hospital ( $\mathrm{n}=42)$, October, 2018.

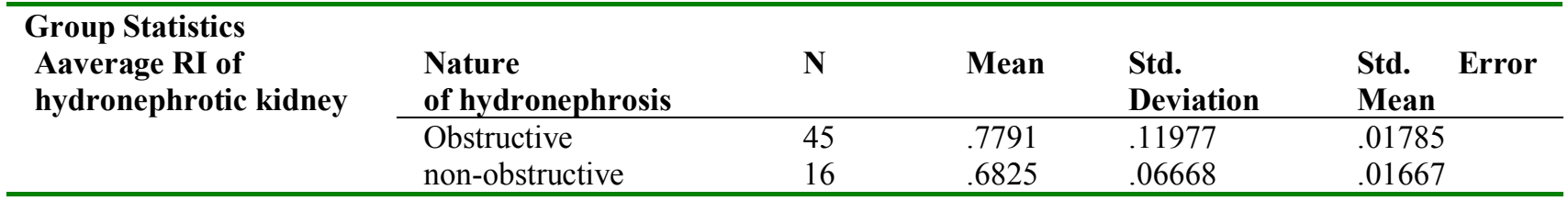

$(\mathrm{P}-<0.001)$

The test confirmed a significant difference between mean RI of obstructive and nonobstructive hydronephrosis, but Levine's test of equality of variance disproved the equality of the variances between the groups. No statistically significant difference was found between the degree of hydronephrosis and mean RI. The mean RI for untreated obstructive hydronephrosis was $0.8347 \pm 08626$ while that of surgically corrected hydronephros was $0.7100 \pm 0.129$, depicting a significant difference $(\mathrm{p}=0.004)$.

Table 2: Comparison of this study's mean Doppler RI of obstructed and non-obstructed hydronephrosis with other similar studies. October, 2018.

\begin{tabular}{lccccc}
\hline Study & \multicolumn{1}{l}{$\begin{array}{l}\text { Total } \\
\text { No of kidneys }\end{array}$} & \multicolumn{3}{c}{ Obstructed } & Non-obstructed \\
\cline { 2 - 6 } & RI \pm SD & \multicolumn{1}{c}{ RI \pm SD } & N \\
\hline Okada et.al (2001) (31) & 22 & .84 & 7 & .65 & 15 \\
Svitac et al (34) & 19 & .77 & 11 & .69 & 8 \\
Kessler etal (1993) (33) & 36 & $.77 \pm 0.05$ & 20 & $.63 \pm .06$ & 16 \\
Mallek et al (35) & 20 & $0.77 \pm 0.03$ & 8 & $.63 \pm .0 .08$ & 12 \\
Platt et a 1(1989) (16) & 21 & $0.77 \pm 0.04$ & 14 & $.64 \pm .04$ & 7 \\
Our Study (2018) & 61 & $0.7791 \pm .119$ & 45 & $.6825 \pm .066$ & 16 \\
\hline
\end{tabular}

Table 3: Comparison of sensitivity specificity and accuracy of Doppler US of this study with studies from published literature review.

\begin{tabular}{lllll}
\hline Investigator & Sample size(unit kidney) & Sensitivity & specificity & Accuracy \\
\hline Kessler et al 1993:(33) & 36 (20 obstructed) & $100 \%$ & $94 \%$ & \\
Platt et al: 1993 (16) & $21(14$ obstructed) & $92 \%$ & $88 \%$ & \\
Brikjacck et al: 2012 (36) & 29(17 obstructed) & $70 \%$ & $92 \%$ & \\
Misni et al: 2015 (17) & $19(6$ obstructed) & $93 \%$ & $53 \%$ & \\
Our study & 61 (45 obstructed) & $71 \%$ & $81.2 \%$ & $75.4 \%$ \\
\hline
\end{tabular}

DOI: http://dx.doi.org/10.4314/ejhs.v29i5.9 
Using 0.7 as the cut-off point area under the ROC curve, RI was 0.754 with CI 0.626-0.882, and a P-

the test with a sensitivity and specificity of $71.1 \%$, value of 0.003 . This was equivalent to accuracy of

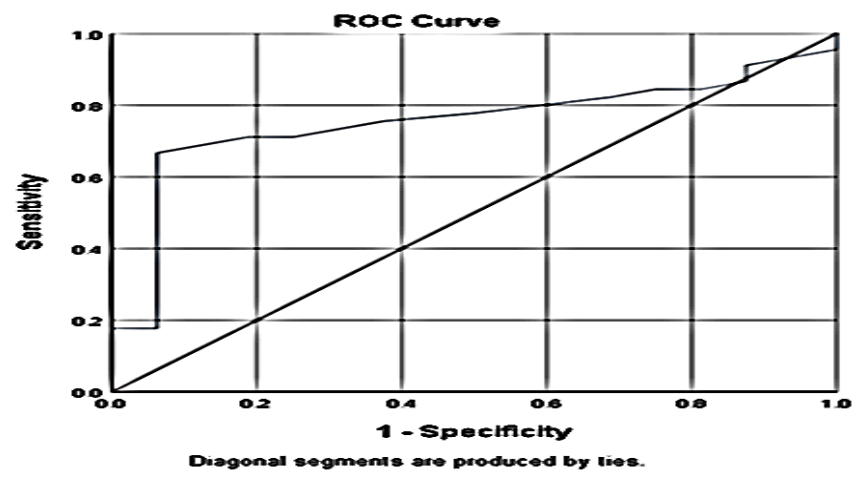

Figure 3: ROC curve analysis among children in Tikur Anbessa Specialized Hospital (n=42), October, 2018 (Using 0.7 as cut off point area under the ROC curve of RI 0.754 with CI 0.626-0.882, P-value of 0.003).

\section{DISCUSSION}

Obstructive hydronephrosis was observed more in males possibly due to PUV obstruction which is common and exclusive in the male gender. PUJ obstruction was also more common in males, particularly infant males were affected five times more than their female counterparts. This observation was in agreement with Peter's findings (12).

In this study, the most common cause of the obstructive hydronephrosis was PUJ obstruction followed by PUV. This was also observed by Palmer (7) in contrast to a study by Okada showing PUV to account for only $1-2 \%(23)$.

In this study, hydronephrosis was mainly detected by ultrasound while nature and etiology were confirmed by IV and surgery for PUJ obstruction and VCUG for PUV and VUR. This was consistent with Hashim's observation (24). However, other studies used nuclear scintigraphy as gold standard to confirm obstructive versus; no obstructive hydronephrosis found depending on the calculation of half time drainage (24).

MRU was not used as diagnostic test in this study because of sedation and long scan time. Duplex Doppler ultrasound is a tool which can provide useful information about renal hemodynamics with no radiation concern. Obstruction causes a decrease in vascular flow due to increase in vascular resistance. Hence, the use of Doppler can be of immense importance in our setup since we do not have nuclear scintigraphy.

This study has shown a significant RI difference between the obstructive and non- obstructive hydronephrosis; the result is consistent with similar studies (16,17,23-29) as shown above (Table 2). These studies used $0.7 \mathrm{RI}$ as discriminator and have found good sensitivity, specificity and diagnostic accuracy $(16,17,25-29)$. Our study has also shown similar results (Table 3). The above comparative table shows that our study had even better sample size with increased statistical power.

In conclusion, this study has shown that the mean renal arterial RI was significantly higher in obstructive hydronephrotic kidneys than non-obstructive hydronephrotic ones. This findingcould be a valuable diagnostic tool in our setting and employed for followup after corrective surgery. We recommend its introduction in the workup of hydronephrosis. We also encourage future population-based and age-stratified studies to produce a normal RI normogram for wider use in clinical decision making.

\section{ACKNOWLEDGEMENTS}

We would like to express our gratitude to the staff, and residents of the Department of Radiology of TASH for facilitating our work during the study.

\section{REFERENCES}

1. Halek J, et al. Diagnostic accuracy of postnatal ultrasound screening for urinary tract abnormalities. PediatrNephrol, 2010: 25(2):281-7.

2. Lee RS, et al:. Antenatal hydronephrosis as a predictor of postnatal outcome: a meta-analysis. Pediatrics, 2006; 118(2):586-93. 
3. Mallik M, Watson AR. Antenatally detected urinary tractabnormalities: more detection but less action. PediatrNephrol, 2008: 23 (6):897-904.

4. Chertin B, et al. Conservative treatment of ureteropelvicjunction obstruction in children with antenatal diagnosis of hydronephrosis: lessons learned after 16 years of follow-up. EurUrol, 2006: 49 (4):734-8.

5. Madden NP, et al. Antenatally detected pelviureteric junction obstruction. Is non-operation safe? Br J Uro, 1991: 68 (3):305-10.

6. Dhillon HK. Prenatally diagnosed hydronephrosis: the Great Ormond Street experience. Br J Urol, 1998: 81(Suppl. 2):39-44.

7. Palmer LS, Maizels M, Cartwright PC, Fernbach SK, Conway JJ. Surgery versus observation for managing obstructive grade 3 to 4 unilateral hydronephrosis: a report from the Society for Fetal Urology. J Urol, 1998:159:22-8.

8. Brophy MM, Austin PF, Yan Y, Coplen DE. Vesico-ureteral reflux and clinical outcomes in infants with prenatally detected hydronephrosis. $J$ Urol, 2002: 168:1716-19.

9. Gloor JM, et al: The association of isolated mild fetal hydronephrosis with postnatal vesicoureteral reflux. J Matern Fetal Neonatal Med, 2002: 12(3):196-200.

10. McLellan DL, et al. Rate and predictors of spontaneous resolution of prenatally diagnosed primary non-refluxing megaureter. J Urol, 2002: 168 (5):2177-80.

11. Shukla AR, et al: Prenatally detected primary megaureter: a role for extended followup. $J$ Urol, 2005: 173:1353-56.

12. Peters CA, et al: The role of the kidney in lung growth and maturation in the setting of obstructive uropathy and oligohydramnios. J Urol, 1991: 146(2): 597-600.

13. Giles R H, Uren R, Roy L P, Filmer R B: Volume expansion diuretic renal scan in urinary tract obstruction: J Nucl Med, 1987: 28(5):824-828.

14. MAGNETOM Flash . 2/2011 www.siemens.com/magnetom-world.

15. Carol M. Rumack et al diagnostic ultrasound $4^{\text {th }}$ edition. 2011 by Mosby, Inc., an affiliate of Elsevier Inc.pp1875-1876.

16. Platt J.F., Rubin, J.M., Ellis, J.H. et al. Duplex Doppler US of the kidney: differentiation of obstructive from nonobstructive dilatation. Radiology, 1989; 171(2):515-7

17. N. Misniet al.Renal Doppler assessment in differentiating obstructivefrom non-obstructive hydronephrosis in children .Med $J$ Malaysia, 2015:70(6):1192-4.

18. Bude, R.O., DiPietro, M.A., Platt, J.F. et al. Age dependency of the renal resistive index in healthy children. Radiology, 1992:184:469-473.

19. H.T. Nguyen et al. the society for fetal urology consensus statement on the evaluation and management of antenatal hydronephrosis: 2010 Journal of Pediatric Urology Company. Published by Elsevier Ltd.

20. Platt, J.F., Ellis, J.H., and Rubin, J.M. Assessment of internal ureteral stent patency in patients with pyelocaliectasis: value of renal duplex sonography. Am J Roentgenol (AJR), 1993; 161(1):87-90.

21. Shokeir, A.A., Nijman, R.J., el-Azab, M. et al. Partial ureteral obstruction: role of renal resistive index in stages of obstruction and release. Urology, 1997; 49:528-35.

22. Ordorica, R.C., Lindfors, K.K., and Palmer, J.M. Diuretic Doppler sonography following successful repair of renal obstruction in children..J Uro,. 1993; 150:774-77.

23. Choi YH, Cheon JE, Kim WS, Kim IO. Ultrasonographyofhydronephrosis in the newborn: a practicalreview. Ultrasonography, 2016: 35(3):198-211.

24. Okada T et al: Pulsed Doppler sonography of the hilar renal artery: Differentiation of obstructive from non-obstructive hydronephrosis in children: Journal of Pediatric Surgery, 2001: 36(3):416-420

25. Hashim H, Christoper R J: Uretero-pelvic junction obstruction: European Urology Supplement, 2012: 11(2):25-32.

26. Kessler RM, Quevedo H, Lankau CA, et al. Obstructive vsnonobstructive dilatation of the renal collecting system in children: distinction with duplex sonography. Am J Roentgenol (AJR). 1993; 160(2):353-7.

27. Svitac J, Zibolen M, Kliment J, et al. Renal Doppler ultrasonography in infants with hydronephrosis. Int Urol Nephrol, 2001; 33(3):431.

28. Mallek R, Bankier AA, Etele-Hainz A, et al. Distinction between obstructive and nonobstructive hydronephrosis: value of diuresis duplex Doppler sonography. Am J Roentgenol (AJR) , 1996; 166(1):113-7.

29. Kuzmic AC, Dmitrovic R, et al. Doppler sonographicrenalresistance index and resistance index ratio in children and adolescentswith unilateral hydronephrosis. EurRadiol, 2002; 12(11):2747-51. 